\title{
Solar Street Light Controller for Harsh Environments
}

\author{
Ping Xue ${ }^{1}$, Yan-liang Song ${ }^{2}$ and Hong-min Wang ${ }^{1}$ \\ School of Automation \\ Harbin University of Science and Technology, Harbin, China, 150080 \\ Corresponding Author: Yan-liang Song \\ syl948936122@163.com
}

\begin{abstract}
At present, solar street light controller has the issues of unscientific discharge policy widely. Especially in the bad weather conditions, such as cold, Continuous rainy days etc. because of the weather conditions not considered comprehensive, causing the system can't be targeted scientifically discharge, thereby making the system operating time is shorter. To solve this problem, the subject has a more depth research, adding the ambient temperature, rainy weather which having a greater impact on the system to the study, Proposed a solutions of based on improved BP neural network algorithm which depending on the temperature, weather conditions and other factors to determine the discharge power of system to achieve the purposes of maximum energy saving. Finally, the simulation experiment shows that the controller compared with the traditional controller can better cope with the severe environment. It has a strong practical value.
\end{abstract}

Keywords: Solar street light controller; Improved BP neural network; harsh environment; alpine; continuous rainy days

\section{Introduction}

Solar photovoltaic power generation system uses the photovoltaic effect principle of photovoltaic cells. During the day, solar photovoltaic cells save converted electrical energy to batteries; night, the battery releases energy to supply lighting system. Solar street lighting system has four major components: LED lamps, lead-acid batteries, controller and photovoltaic cells. Wherein the controller is the core of the lighting system, the quality of the controller not only affect the life of the battery but also affects the sustainable lighting systems, at present, the market's controllers is not all things considered about the influencing factors of solar lighting system, For example, Due to the lack of in-depth study on the lighting system of harsh environments such as cold, rainy days in a row, so, the system can't charge and discharge efficiently according to the environmental changes and the system can't work persistently due to the lack of storage energy. For the above, to find an efficient control strategy, this project have had a depth research about the impact of factors such as alpine and daytime charging amount of the system, to meet the requirements of street lighting, the extension of the system lighting time, saves energy, has a strong practical value. In this paper, the improved BP neural network algorithm which simulated biological nervous system, according to the current external environment to make decisions intelligently and control system to work efficiently and reliably.

\section{The Study of the Control Strategy}

Currently, most street light controllers have been controlling LED lights simply by one-touch control, dark on the open, dawn that off. Excellent performance of the 
controller can automatically adjust system output power based on the remaining power and the light or dark of weather of lead-acid batteries and energy-saving are achieved. Although has certain intelligent of the controller, in the face of bad weather, yet not be truly scientific discharged. The topic of solar street light controller have made a further study, we have joined the factors of affecting the system to the study, such as the amount of charge during the day, ambient temperature, etc. and have been decided the power of discharge more intelligent and more comprehensive according to its own situation and the external environment. Like a personal control the street lighting real-time under the circumstances.

\subsection{The Amount of Charge A Day}

The amount of charge a day, that is during the day, how much solar energy is converted to electrical energy. The formula is: $\mathrm{Q}=, \int_{0}^{t} \operatorname{sidt}$ in it, i stand for the charging current, $\varepsilon$ is for the charge and discharge efficiency. The day's weather conditions reflected on the amount of charge during the day, Q is the amount of charge, the greater it is, expressed more sunny weather that day, on the contrary, represents the dark weather. The issue, when the $\mathrm{Q}$ value is less than $14.5 \mathrm{AH}$, indicating the amount of charge that day system is less than the average amount of discharge system at night, the night need to save energy, if continuously lower than $14.5 \mathrm{AH}$, it is further reducing the discharge amount.

\subsection{Ambient Temperature}

The rated capacity of the battery is at $25{ }^{\circ} \mathrm{C}$, under specified discharge rate specified conditions. When the ambient temperature is different, the discharge capacity of the battery (chemical reaction efficiency of the active substance inside the battery) will be different too.

The relationship between Battery capacity and ambient temperature as follows:

$$
Q=Q t /[1+K(T-25)]
$$

(1)

Where, Q is the nominal capacity at $25{ }^{\circ} \mathrm{C}$; Qt is measured capacity; $\mathrm{T}$ is the actual ambient temperature; $\mathrm{K}$ is temperature coefficient, when the discharge hour rate greater or equal to $10 \mathrm{H}$, then $\mathrm{K}=0.006 /{ }^{\circ} \mathrm{C}$. From the above equation, the lower the temperature, the battery capacity is smaller. For example, when the temperature is reduced from $25{ }^{\circ} \mathrm{C}$ to $0{ }^{\circ} \mathrm{C}$, the capacity dropped 15 percent; the temperature is reduced from $25{ }^{\circ} \mathrm{C}$ to $-25{ }^{\circ} \mathrm{C}$, the capacity even declined about 30 percent, it shows that the ambient temperature of the battery capacity has not be ignored Impact. The issue of power load operation decisions based on changes in ambient temperature, as the temperature decreases, the operating power load is also appropriate to reduce, so as to achieve the purpose of extended lighting time.

According to "the standards of city road lighting design" requirement; Average illumination of fast road and trunk road are $20 / 30 \mathrm{Lx}$, evenness 0.4 ; secondary road is 10 / 15Lx, evenness 0.35 ; branch road is $8 / 10 \mathrm{Lx}$, evenness 0.3. The topic was designed as the secondary road design, road illumination at least not less than 10Lx. Correspondence between the night of photovoltaic cells between the line voltage and illumination shown in Figure 1: 


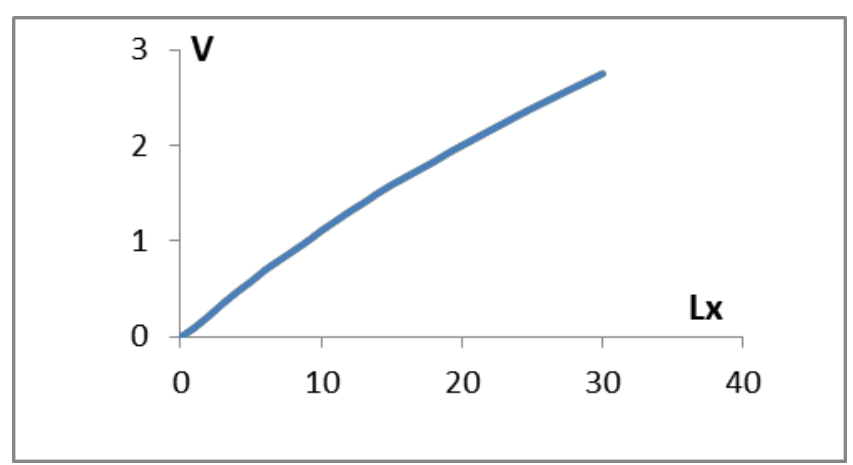

Figure 1. Correspondence between the Voltage and Illumination

Currently, the discharge power control system according to the battery SOC and weather light or dark controllers matching methods commonly used to control the output power programming. First, put the relational data between the line voltage of battery SOC and photocells and battery output power into the stored in the storage area, then, controller will contrast of line voltage by the photovoltaic cells and the battery SOC with the data of storage area. At last, obtain the discharge output power by matching results. This method is widely used when there is less input and output variables, it is simple and easy to implement. However, in this study, not only taking into account the SOC, weather and bright or dark discharge power relations, but local time, ambient temperature, the amount of charge during the day and other factors are also study. The more variables, the huger of relationship between the variables, and therefore, this method is no longer applicable in the present issue. This topic will be the improved according to BP neural network algorithm, simulate the human brain thinking, control the system discharge process.

\section{The Improved Neural Network Algorithm}

Artificial neural network, referred to as neural networks (English name: Neural Network), the theoretical results was proposed through in-depth research on the human brain and simulation of the thinking process of the human brain, this method can simulate well the human brain and thinking behavior. The issue, to the amount of charge during the day, ambient temperature, storage Battery SOC, bright and dark of the weather as well as local time and other factors as the input into the control scheme, operating power load as output, comprehensive consideration, repeated experiments and obtained the optimal scheme of control strategy. The use of artificial neural network to control scheme of mathematical modeling caused the controller to achieve high-level intelligence purposes.

\subsection{Neural Network Model}

Each model is composed of a network of neurons is expressed as follows:

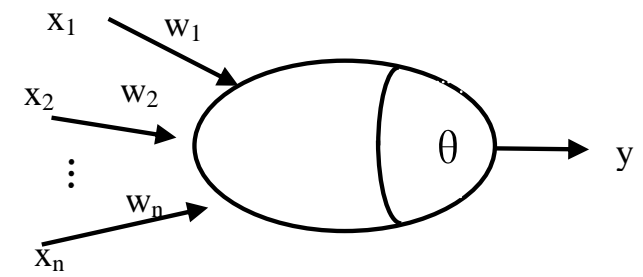

Figure 2. Neural Network Model 
Model having a plurality of inputs, $\mathrm{i}=1,2, \ldots, \mathrm{n}$ and a single output $\mathrm{y}$, the internal state of the model is given by the weighted sum of input signal. The output of the neural circuits can be expressed as follows: $y(t)=f\left(\sum_{i=1}^{n} w_{i} x_{i}(t)-\theta\right)$, where $\theta$ is the threshold nerve cells, $\mathrm{n}$ is the number of input, $\mathrm{t}$ is the time, the weights represent the strength of the connection, indicating that the synapse load. Output functions usually take 1 and 0 binary function or continuous, nonlinear Sigmoid function.

\subsection{BP Neural network}

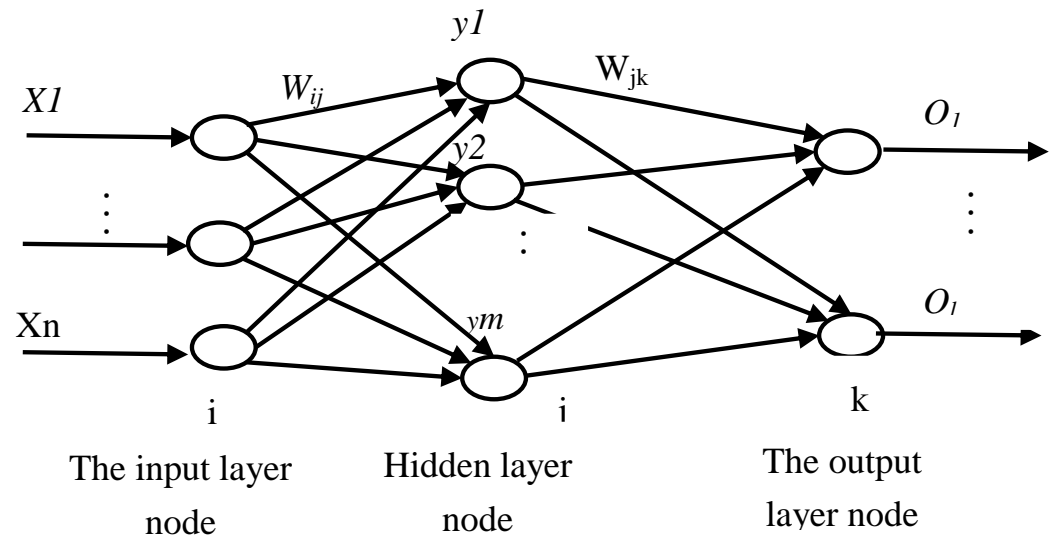

Figure 3. BP Neural Network

BP network structure containing a hidden layer as shown above, $\mathrm{X}$ is the input vector, $\mathrm{Y}$ is a hidden layer output vectors, $\mathrm{O}$ is the output layer output vector.

\subsubsection{Forward Propagation:}

The calculation of the output and the error of the network

hidden $\quad$ layer: $\quad y_{j}=f\left(\right.$ net $\left._{j}\right)=f\left(\sum_{i=0}^{n} W_{i j} X_{i}\right) \quad \mathrm{j}=1,2,3, \ldots, \mathrm{m}$

output layer: $O_{k}=f\left(\right.$ net $\left._{k}\right)=f\left(\sum_{j=0}^{m} W_{j k} y_{j}\right)==f\left(\sum_{j=0}^{m} W_{j k} f\left(\sum_{i=0}^{n} W_{i j X i}\right)\right)$

$$
\mathrm{j}=1,2,3, \ldots, \mathrm{m} ; \mathrm{k}=1,2,3, \ldots, 1
$$

(3)

The above two type adopt the function of sigmoid.

$$
f(x)=\frac{1}{1+e^{\wedge}(-x)}
$$




$$
f^{\prime}(x)=f(x)[1-f(x)]
$$

The error of the Network actual output and ideal output:

$e(k)=O_{k}-T_{k} \quad \mathrm{O}_{\mathrm{K}}$ is actual output of network; $\mathrm{T}_{\mathrm{K}}$ is ideal output

The function of error performance:

$E=\frac{1}{2} e(k)^{2}=\frac{1}{2} \sum_{k=1}^{l}\left\{T_{k}-f\left[\sum_{j=0}^{m} w_{j k} f\left(\sum_{i=0}^{n} w_{i j} x_{i}\right)\right]\right\}^{2}$

(6)

It can be seen, the output error has a relationship with the weights of hidden layer and output layer.

\subsubsection{Reverse Propagation:}

Use $\delta$ algorithm, adjust the weights between the layers.

Connection weights of the output layer and the hidden layer:

$$
\Delta W j k=-\eta \frac{\partial E}{\partial W}=-\eta \frac{\partial E}{\partial O} * \frac{\partial O}{\partial W}==\eta\left(T_{k}-O_{k}\right) O_{k}\left(1-O_{k}\right) y
$$

Wherein, $\eta$ is the learning rate; $\eta \in[0,1] ; \quad j=1,2, \ldots, m ; \quad k=1,2, \ldots, 1$

(7)

Hidden layer and input layer connection weights

$$
\Delta W_{i j}=-\eta \frac{\partial E}{\partial W_{i j}}=\eta\left[\sum_{k=1}^{l}\left(T_{k}-O_{k}\right) O_{k}\left(1-O_{k}\right)_{W_{j k}}\right]_{y_{j}}\left(1-y_{j}\right)_{X_{i}}
$$

Wherein, $\eta$ is the learning rate; $\eta \in[0,1] ; i=1,2, \ldots, n ; j=1,2, \ldots, m ; k=1,2, \ldots, 1$ (8)

\subsubsection{The Signal flow of BP Algorithm}

The calculation of the forward and backward error propagation of the BP algorithm signal flow. The forward process signals are: the signal transmit from the input nodes, after weighted calculation, transmitted to hidden layer node and then pass to the output layer from hidden layer after weighted calculation; The back-propagation process signals are: comparing the desired output and the actual output and then get the output error signal e. Thus, we can calculate the adjustment amount of output layer weights. Error signal e via the weight vector of each node in hidden layer to the hidden layer nodes, and get the error signal e of hidden layer, which we can calculate the amount of the adjustment of weights of the hidden layer.

\subsection{Improved BP Network Algorithm}

BP neural network with nonlinear mapping, self-learning ability and other advantages, however, with the expansion of the scope of application, the BP network also exposed such as slow convergence speed, easy to fall into local minimum not allow to ignore the shortcomings, BP neural network is based on the error - correction of learning, the learning rate of convergence have a significant impact on the network, in order to achieve 
the desired learning rate, this paper presents optimization functions BP network learning rate, the formula is as follows:

$$
\eta=\frac{\varepsilon|\Delta E|}{\sqrt{\left(\frac{\partial E}{\partial W}\right)^{2}+\left(\frac{\partial E}{\partial \theta}\right)^{2}}}
$$

(9)

Wherein, $\Delta E$ is a network error, $\varepsilon$ is the correction factor, is the training error curve steepness. In this paper, the improved rate of self-learning $\sqrt{\left(\frac{\partial E}{\partial W}\right)^{2}+\left(\frac{\partial E}{\partial \theta}\right)^{2}}$ network to automatically adapt to changes in error and training error $\sqrt{\left(\frac{\partial}{\partial W}\right)^{2}+\left(\frac{\partial}{\partial \theta}\right)^{2}}$ curve steepness is conducive to network training to avoid local minimum and speed up the convergence speed.

\section{The Control Strategy of Experiment}

This paper uses a voltage of $12 \mathrm{~V}$, capacity $54 \mathrm{Ah}$ lead-acid batteries; maximum output power $75 \mathrm{~W}$, maximum voltage of $21.8 \mathrm{~V}$ PV cells; rated voltage of $12 \mathrm{~V}, 28 \mathrm{~W}$ power LED lights.

In order to obtain the best user experience and optimal control strategy, this topic members place battery frozen ark, artificially adjust the ambient temperature and control the amount of photoelectric conversion cell. Through a lot of experiments, we obtained that meets the user experience but also the experimental data for maximizing solar street lighting system up time. The following is part of the experimental data:

Table 1. Sample Data

\begin{tabular}{|c|c|c|c|c|c|}
\hline $\begin{array}{c}\text { Time has } \\
\text { been } \\
\text { working } \\
(\mathrm{H})\end{array}$ & $\begin{array}{c}\text { SOC } \\
(\%)\end{array}$ & $\begin{array}{c}\text { Photocell } \\
\text { line } \\
\text { voltage(V) }\end{array}$ & $\begin{array}{c}\text { The amount of } \\
\text { charge during } \\
\text { the day(A*H) }\end{array}$ & $\begin{array}{c}\text { Ambient } \\
\text { temperature }\left({ }^{\circ} \mathrm{C}\right)\end{array}$ & $\begin{array}{c}\text { LED } \\
\text { discharge } \\
\text { power }(\%)\end{array}$ \\
\hline 1 & 91 & 0 & 15.6 & -21 & 100 \\
\hline 1 & 95 & 0.37 & 13.1 & -18 & 80 \\
\hline 4 & 61 & 0.69 & 14.5 & -20 & 55 \\
\hline 2 & 90 & 0.34 & 17.1 & -5 & 85 \\
\hline 1 & 55 & 0 & 30.2 & 0 & 100 \\
\hline 8 & 74 & 0 & 18.1 & 17 & 65 \\
\hline 8 & 64 & 0 & 30.1 & 0 & 65 \\
\hline 6 & 35 & 0.8 & 9.7 & 10 & 15 \\
\hline 3 & 65 & 0 & 15.7 & 20 & 90 \\
\hline 1 & 70 & 0.47 & 10.0 & 23 & 70 \\
\hline 8 & 30 & 1.11 & 2 & 8 & 0 \\
\hline
\end{tabular}




\section{The MATLAB Simulation and Data Analysis of BP Neural Network}

\subsection{Network Design}

This topic has adopted the working time of LED, SOC, light or dark of weather, the charged amount during the day, ambient temperature, etc., as analog input, the load power as the simulation output. In order to avoid the network prediction error is large because of the larger order of magnitude difference between the input and output data, this article will deal with the data normalized to eliminate the order of magnitude difference between the dimensional data.

3-layer network design as the subject of the simulation model is selected. Hidden nodes set to 4 , the transfer function of the input and output nodes are selecting S-type transfer function of logsig. Training error is $5 * \mathrm{e}-3$;

\subsection{Network Simulation Result Analysis}

This topic has chosen 200 groups of sample data to train the network, 20 groups of data as check samples. Figure 4 and Figure 5 is the improved network training curve before and after:

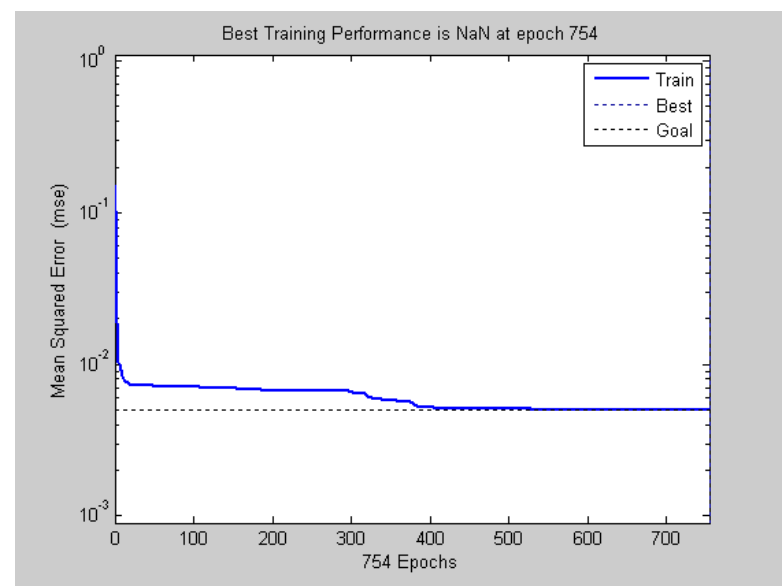

Figure 4. Improved BP Network Ago

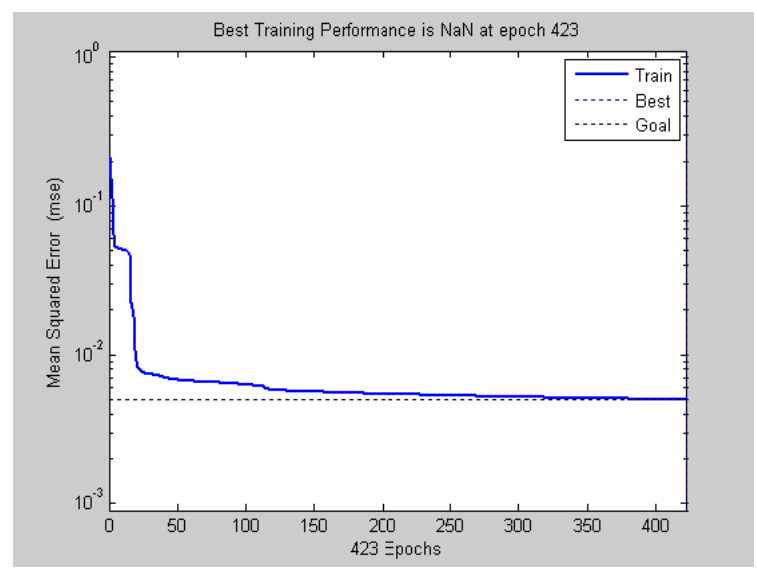

Figure 5. Improved BP Network 
As it can be seen from the figure, the speed of convergence improved BP network is faster significantly than before. Before the improved network convergence accuracy is 0.0050 , after improved to 0.0048 .

Figure 6 is a comparison chart of the system predicted output power value and the sample value.

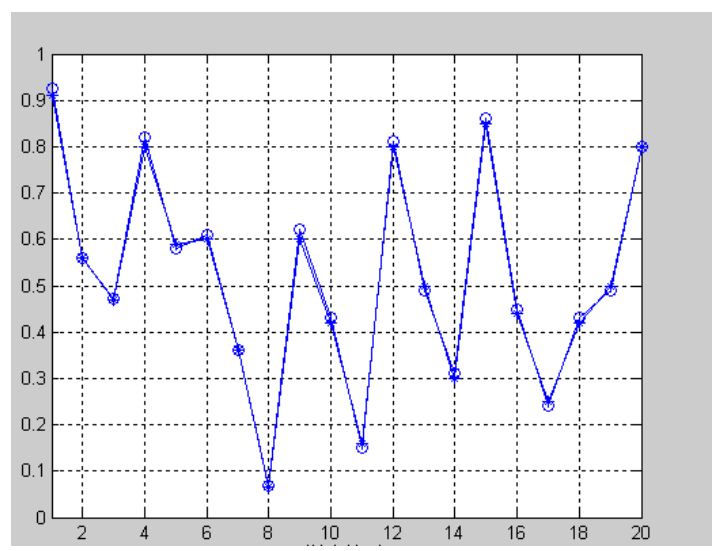

Figure 6. Comparison of the Simulation Results

Figure 6 shows that the actual output of the system is expected between output power and system power output error is less than $2.2 \%$.

\subsection{Analysis Of Experimental Results}

To set the conventional controller load power with $100 \% 5$ hours before, with $80 \%$ of the power work the following 3 hours, with $65 \%$ of the power work before dawn. After connecting the external device, the full power of the battery and the controller on freezers, photovoltaic cells placed in a chamber to achieve human control weather light and dark, the controller then equal conditions of access to the subject design, obtain the following data:

Table 2. Experimental Data

\begin{tabular}{|c|c|c|c|}
\hline $\begin{array}{c}\text { The amount of } \\
\text { charge during } \\
\text { the day }\left(\mathrm{A}^{*} \mathrm{H}\right)\end{array}$ & $\begin{array}{c}\text { Freezer } \\
\text { temperature } \\
\left({ }^{\circ} \mathrm{C}\right)\end{array}$ & $\begin{array}{c}\text { Traditional } \\
\text { controller } \\
\text { working time }(\mathrm{h})\end{array}$ & $\begin{array}{c}\text { This topic controller } \\
\text { working time }(\mathrm{h})\end{array}$ \\
\hline 0 & 25 & 25.2 & 29.3 \\
\hline 0 & 0 & 22 & 26.6 \\
\hline 0 & -20 & 19.1 & 24 \\
\hline 15 & 25 & 122.4 & Continuous lighting \\
\hline 15 & 0 & 109.5 & Continuous lighting \\
\hline 15 & -20 & 98.7 & Continuous lighting \\
\hline
\end{tabular}

By the experimental data shows that this controller can better adapt to harsh environments than conventional controller 


\section{Conclusions}

In this issue, the use of artificial network algorithm controller compared with traditional controllers, at least $20 \%$ energy saving, after long practice tests have proved that the controller is stable and reliable, can better cope with the harsh weather conditions, with a very strong practicability.

\section{Acknowledgement}

This work is supported by Natural Science Foundation of Heilongjiang Province of China under Grant Nos. F201310 and Special fund for scientific and technological innovation talents of Harbin under Grant Nos. RC2013Q0009007 and Research and development project of Heilongjiang Province under Grant Nos. GC13A412

\section{References}

[1] H. Y. Kanaan and K. AI-Haddad, "Modeling and Simulation of DC-DC Power Converters in CCM and DCM Using the Switching Functions Approach: Application To the Buck and Cuk Converters", Power Electronics and Drives Systems, International Conferonce, (2005).

[2] W. B. Wang and C. X. Yang, "Design and Simulation Based on Advanced BP Algorithm Decoupling Controller of Heat Network", Journal of Harbin University of Science and Technology, (2012), pp. 58-62.

[3] J. Gu and L. Y. Liu, "The Research of Multivariable Fuzzy Neural Network Controller Based on FPGA”, Journal of Harbin University of Science and Technology, (2011), pp. 44-48.

[4] T. F. Wu, C. H. Chang and Y. H. Chen, "A fuzzy-logic-controlled single-stage converter for PV-powered lighting system application”, IEEE Transactions on Industrial Electronics, (2000).

[5] K. K. Tse, "A Comparative Study of Maximum-Power-Point Tracker for Photovoltaic Panel Using Switching-Frequency Modulation Scheme", IEEE Trans on Electron, vol. 51, no. 2, (2004), pp. 410-418.

[6] M. Veerachary, T. Senjyu and K. Uezato, "Voltage-based Maximum Power Point Tracking Control of PV System”, IEEE Trans. on Aerosp. Electron. Syst, vol. 38, no. 1, (2002), pp. 262-270.

[7] Q. Y. Cheng and B. Chen, "LED solar street lamps controller design", Science and technology innovation herald, vol. 12, (2011), pp. 6-7.

[8] M. H. Yu, J. Y. Zheng and X. F. Zhang, "Efficient solar charge controller research", Jiangsu electrical appliances, vol. 3, (2008), pp. 15-18.

[9] Z. M. Zhou and J. A. Hua, "Solar LED street lamp design and application", Beijing: electronic industry press, (2009).

[10] L. B. Wu, J. Z. Liu and J. Wang, "The power electronics application in solar street lighting systems", Power electronics, vol. 1, no. 2, (2003), pp. 15-19.

[11] P. Zhao, Z. M. Zhao and D. J. Zhou, "Status and development of solar photovoltaic power generation", Electrical applications, vol. 26, no. 10, (2007).

[12] K. Hua and Y. Li, "Solar LED street lamp controller design", Journal of MCU development and application, vol. 25, no. 12, (2009), pp. 105-107.

[13] J. Z. He, "The solar street light system optimization design", Journal of renewable energy, vol. 5, (2007), pp. $79-84$

[14] K. Li, "The study and design of intelligent charger and battery maintenance system", Master thesis of tianjin university of technology, (2007).

[15] K. J. S. Xu, "Solar powe r generation system of DC/DC circuit unit", Journal of new energy, vol. 22, no. 11, (2000), pp. 20-22.

[16] C. N. Zhang, J. H. Zhong and Z. Wang, "Quick charge system of lead-acid battery for electric vehicles", Chinese Journal of Power Sources, vol. 2, (2006), pp. 47-50.

[17] G. C. Bandara, R. Ivanov and S. Gishin, "Intelligent Fuzzy Controller for a Lead-Acid Battery Charger, Systems, Man, and Cybernetics”, Proceedings of IEEE SMC Conference, (1999). 
International Journal of Smart Home

Vol. 9, No. 12, (2015) 